\title{
Finding 'Reasons to Stay' Amidst Issues of Well-Being: A Case Study of Two Underserved Communities in Colombo
}

\section{Iresha M. Lakshman}

(Associate Professor, PhD)

Department of Sociology, University of Colombo

\section{Mohideen M. Alikhan}

(Senior Lecturer, MPhil)

Department of Geography, University of Peradeniya

\section{Abdhullah Azam \\ (Research Assistant, BA) \\ Centre for Migration Research and Development}

Submitted: 12 October 2020

Accepted: 16 November 2020

Published: 31 December 2020

Corresponding author:

Iresha M. Lakshman

DOI: 10.19044/esj.2020.v16n35p94

(c)

Copyright 2020 Lakshman I. M. et al.

Distributed under Creative Commons BY-NC-ND 4.0 OPEN ACCESS

This paper was commissioned by the Centre for Migration Research and Development (CMRD). The research was conducted by the CMRD in partnership with the University of Sussex with financial support from the Economic and Social Research Council (ESRC), Arts and Humanities Research Council (AHRC), and the Royal Geographical Society (RGS). The opinions expressed in this work do not necessarily reflect those of the ESRC, AHRC or RGS.

The paper has been published as a working paper by the CMRD.

\section{Abstract}

This paper attempts to explore the factors that attract and encourage individuals to live in low-income neighbourhoods in Colombo in spite of the many socioeconomic issues that are associated with such communities. Data was collected through 30 face-to-face in-depth interviews with residents from two underserved communities consisting of individuals with different migration experiences. The collected data was then analysed using the three-dimensional well-being model introduced by Pouw and McGregor (2014). The study revealed a situation of material and relational wellbeing intersecting to create a more practical kind of well-being in the communities studied. Of the two, material well-being had the strongest power to attract and retain residents in the neighbourhoods while relational wellbeing played a supportive role in terms of pulling people into the community. Subjective well-being, on the other hand, was identified as the strongest reason with a capacity to push people away from the community. However, this single push factor was not strong enough to overpower the pull effect of material and relational well-being, particularly because of the residents' low-income status. The material benefits of living in the location facilitated by social ties offered by the neighbourhood kept these residents attracted and attached to these underserved communities.

Keywords: Migration, low-income settlements, well-being, Sri Lanka 


\section{Introduction}

Migrating into cities has always been viewed as a more lucrative option throughout history across the globe. Colombo city is no exception in this regard. Historically, migration has contributed to growing numbers of residents in Colombo and this trend is likely to become even more significant in years to come with large numbers of rural poor coming into Colombo looking for more lucrative possibilities (Arularasi and Alikhan 2015). The highest number of lifetime internal migrants found in Colombo district is 26.5 per cent; among them 42.8 per cent of migrants move to Colombo for employment (Department of Census \& Statistics 2015).

Colombo has been the central hub of political, economic, and administrative affairs of Sri Lanka since 1815, when the British brought the entire island under single administrative control. As in many countries in the Global South, low-income neighbourhoods in Colombo have their origins in the Colonial Period. The British colonial officers made Colombo a hub of economic and administrative functions, which increased employment opportunities. The expansion of the port in 1883, and its associated industries, was a primary instrument that stimulated the rise of a particular clustering of working-class tenements and small businesses (Van Horen, 2002), . A survey conducted by the Colombo Municipal Council (CMC) and the Sevanatha Urban Resource Centre in 2011 studied 77,612 families living in 1,614 underserved settlements in Colombo. According to a report by Sevanatha (2013), these low-income neighbourhoods contain nearly half of Colombo's population. Since the British period, various attempts have been made to find solutions to issues of congested low-income settlements in Sri Lanka. Unhealthy and overcrowded living standards of the low-income working class have grabbed the attention of the CMC since 1910 (Perera 2008).

This paper attempts to explore the factors that encourage individuals to continue living in these low-income neighbourhoods in spite of the overcrowded living standards that have been recorded by many researchers as leading to certain difficult life situations (D'Cruz, McGranahan, and Sumithre 2009; Horen 2002; Silva and Athukorala 1991). The paper opens with a discussion on the living conditions of people in underserved communities followed by a discussion of the methods of data collection employed in the study. The discussion of findings, guided by Pouw and McGregor's (2014) well-being model, is presented under three main titles, namely material wellbeing, relational well-being, and subjective well-being.

\section{Living Conditions of Low-income Neighbourhoods:}

Underserved communities in Colombo have been recorded to be laden with problems such as drug abuse and dealing, petty theft, abuse of alcohol, frequent verbal and physical fighting and other deviant behaviours. These 
problems are looked upon by residents in these communities as threatening the educational opportunities available to their children and the general wellbeing of all residents (Lakshman, Ekanayaka, and Lakshman 2016; Lakshman, Herath, Alikhan, and Ekanayake 2016). In fact many residents mention a desire to move out from these neighbourhoods. In spite of this desire, some researchers highlight that residents are reluctant to move out from these neighbourhoods even when they are offered free housing or houses at subsidized prices by the Government (Lakshman, Herath, Alikhan, and Ekanayaka 2016). Their dissatisfaction about such kinds of relocation is mostly related to the fact that they feel socially disjointed when their former social relations get disrupted due to relocation/resettlement. This indicates that residents in underserved communities enjoy strong social bonds.

People in low-income neighbourhoods individually and collectively make various attempts to meet essential needs in their everyday life. Roy (2011) considers the slum as a place of collective action. For Roy (2011: 223) the slum is "a terrain of habitation, livelihood, self-organization and politics." In certain places, everyday engagement and interaction among dwellers in low-income neighbourhoods take place for common tasks such as basic infrastructural improvements, security and work (Amin 2013).

The congested nature of urban underserved neighbourhoods, a condition never appreciated by residents, creates the background for a unique kind of social networking. In contrast to wealthier neighbourhoods, interaction between individuals in low-income neighbourhoods is hard to avoid in poorer parts of cities where space is typically limited. Bayat (2008: 180) outlines "proximity" and "interaction" as factors which help different people to socialize with each other. However, generally, underserved settlements are looked at as problematic places, which contain dystopian elements, such as prejudice, violence, drugs, and organized crime (Blau 1960; Brennan-Galvin 2002; Felbab-Brown 2011; Lakshman, Herath, Alikhan, and Ekanayake 2016).

The contrast between the dystopian elements and the existence of strong social bonds within the same community needs some further clarification. Even though slum dwellers are capable of providing for themselves on their own to some extent, working collectively through residential associations and/or community-based organizations help them sustain as individual family units and as communities. Local leaders and politicians manipulate this unstable economic situation coupled with strong communal ties to further their individual and party agendas. The dystopian elements are the result of this kind of manipulation. Congested physical environment and the marginalized social structure of these communities encourage its youth to engage in the abuse of drugs, violence and crimes. As a result emotion and antagonism develop as parts of everyday slum culture. 
Even under these problematic conditions, everyday engagements in these neighbourhoods are observed as leading to well-being and happiness. As pointed out by Datta (2012), the commonly found negative perceptions of underserved settlements fail to recognize the valuable characteristics of such places. Well-being and happiness are broad and vague notions which differ according to people and cultures. Gough and McGregor (2007: 4) state that "well-being is an umbrella concept, embracing at least 'objective well-being' and 'subjective well-being'." Objective well-being is determined by factors external to the respective human community. In contrast, the community's internal characteristics and features determine subjective well-being. Both lead to happiness and are mutually dependent. We all have different meanings for happiness, pleasure, being engaged, and life satisfaction. Well-being and happiness are essential for every human being for ensuring psychological and physical well-being which help to reduce health risks and enhance the lifespan. The more common view is that well-being and happiness are luxurious conditions of life experienced exclusively by wealthy people. People living in low-income neighbourhoods also experience well-being and happiness in everyday life. For example, although per capita income in Bangladesh is low, the level of happiness in Bangladesh is higher than in many other countries including some developed nations (Camfield, Choudhury, and Devine 2009). Another comparative study illustrates that the average life satisfaction was fairly negative among Americans but positive for street inhabitants in Calcutta (Biswas-Diener and Diener 2006).

Rojas (2005: 261) describes that many factors influence overall quality of life and happiness. He states that different people have different definitions of what a happy life is. However, happiness depends on socioeconomic and demographic conditions of a person. People consider that higher levels of income are closely associated with higher levels of well-being as it leads to material accumulation. However, studies show that income does not have a strong influence on well-being and happiness of people (Diener and Suh 2003; Fuentes and Rojas 2001). Another study concludes that income has a close interaction with happiness in developing countries like Bangladesh (Mahmud and Sawada 2018). This study suggests that material well-being should also be uplifted in order to enhance happiness.

Pouw and McGregor (2014) argue that economic growth alone does not improve well-being. In their three dimension of well-being intersecting model, they highlight that other aspects of well-being may suffer when material aspects of well-being improve. Pouw and McGregor (2014: 16) define human well-being as "a state of being with others and the natural environment that arises where human needs are met, where individuals and social groups can act meaningfully to pursue their goals, and where they are satisfied with their way of life." According to this definition they explore well- 
being through three important aspects, namely material, relational, and cognitive/subjective aspects of people's needs and goals in life (Figure 1).

Figure 1. The three dimensions of well-being intersecting

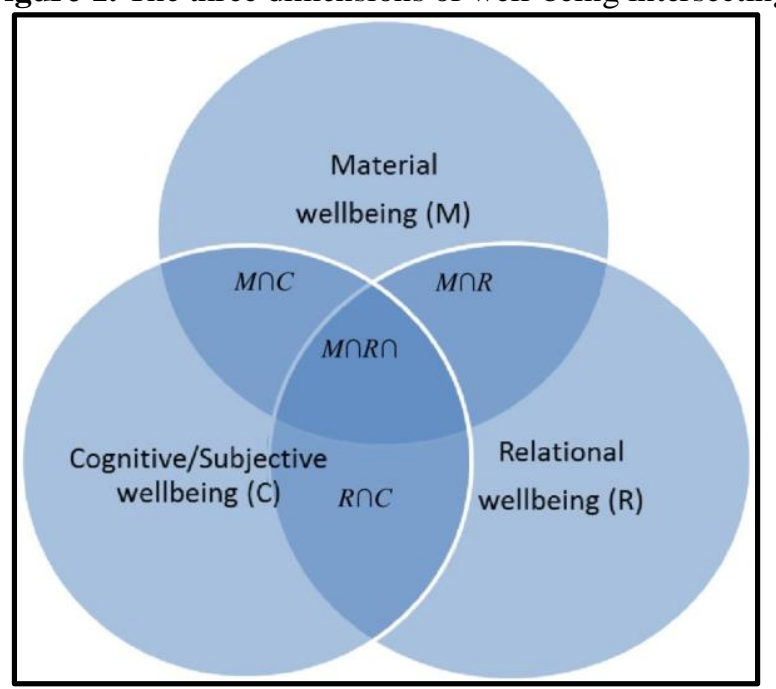

Source: Pouw and McGregor (2014)

The three aspects of well-being can be distinguished according to the above Venn diagram. People's needs and goals may not be satisfactorily fulfilled by means of material (M), relational (R) or cognitive/subjective (C) taken separately. Some people may be satisfied about their life if two of the above aspects are fulfilled, i.e., $(\mathrm{M} \cap \mathrm{R})$ or $(\mathrm{R} \cap \mathrm{C})$ or $(\mathrm{M} \cap \mathrm{C})$. However, Pouw and McGregor (2014) illustrate that most realistic well-being is found through a combination of all three dimensions $(\mathrm{M} \cap \mathrm{R} \cap \mathrm{C})$.

\section{Methods of Data Collection:}

Two underserved settlements with relatively high numbers of migrants were selected for this study, namely Sammanthranapura Grama Niladhari Division from Colombo Divisional Secretariat Division and Wadulla Grama Niladhari Division from Kolonnawa Divisional Secretariat Division (see Figure 2.) These sites consist of multi-ethnic, multi-religious people with different migration experiences such as interurban, intra-urban and ruralurban. These migrants have arrived in these sites voluntarily or involuntarily as relocatees during different periods due to various relocation projects. 1976 city development project for the Non-Aligned Summit and the Peliyagoda bridge expansion project of 1990 are such projects that led to the development and expansion of the two settlements under discussion. Findings reveal employment, marriage, accompanying family members, and relocation as key reasons that brought families into these lands. 
Figure 2. Study sites

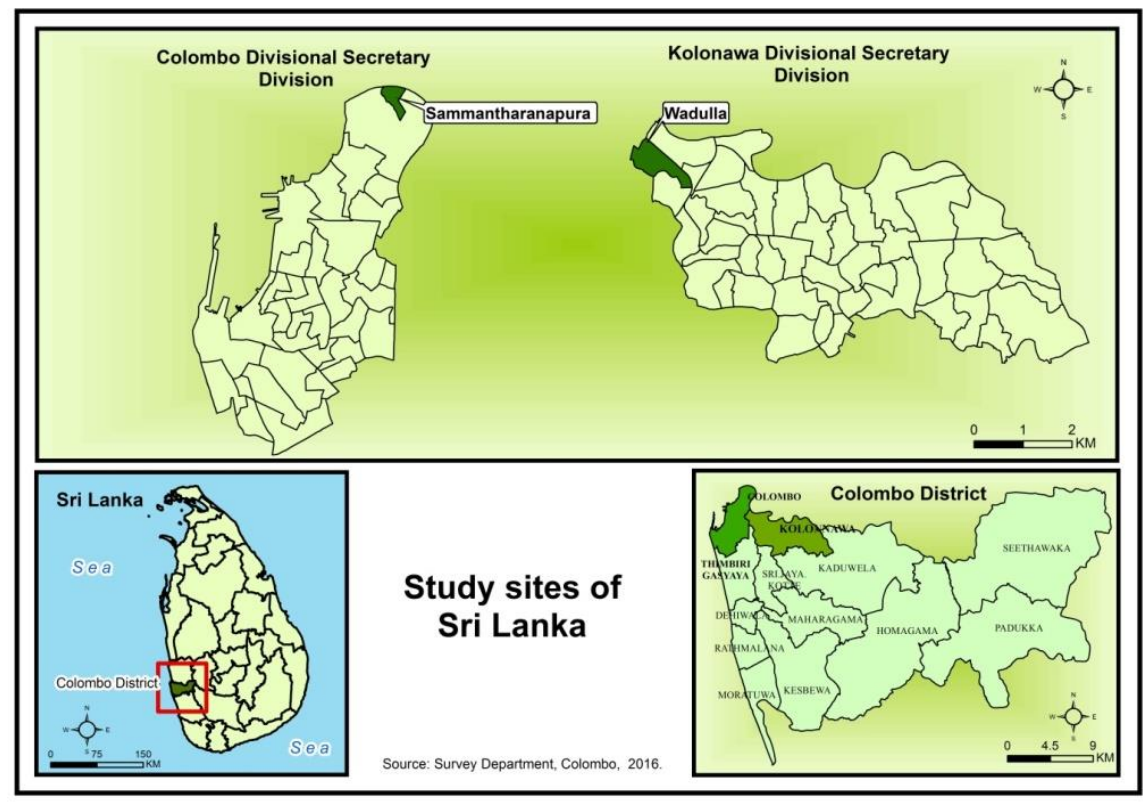

Source: Survey data

Data for this paper was collected mainly through interviews. The activity was ethically cleared ${ }^{1}$ before fieldwork and informed consent received from respondents. Many authors have highlighted benefits of using interviews in a research study of this nature. Qualitative approaches are seen as significant in understanding people's experiences of well-being (Camfield, Crivello, and Woodhead 2009). Interviews have a significant potential to dig deeper and gather more appropriate information when compared with other data collection methods in the qualitative trajectory. Interviews provide space for ordinary people, especially the marginalized, to freely explain their life situations in their own words (Cook 2008; Kvale 2006). It is also a notable method to understand the ways people live in and create their day-to-day lives and social world (Warren 2004). Atkinson (2003: 567) expressed that "a life story narrative can be a valuable text for learning about human endeavour, or how the self evolves over time, and becomes a meaning maker with a place in society, the culture, and history."

Thirty face-to-face in-depth interviews with a purposively selected sample were employed in this research. This paper explores the nature of wellbeing and happiness in the two selected underserved communities in Colombo. The research approached well-being and happiness through the

${ }^{1}$ Ethics clearance for engaging in research with human participants was obtained from an independent committee appointed by the Centre of Migration Research and Development. 
three dimensions of the well-being model introduced by Pouw and McGregor (2014). Questions were formed to address each of the three dimensions and answers received were thematically analysed according to the same three dimensions/ themes. The researchers explored the material dimension of respondents through housing condition, physical environment, and tenure. Subjective well-being was understood through feelings of shame, fear, and tension. Finally, the relational aspect of well-being was understood through social and family networks.

\section{The Study Sites:}

Wadulla Grama Niladhari Division is located in Colombo North, near the Kelani Bridge, which is one of the main entrances to Colombo. Figure 3 highlights the neighbourhood and its prominent features which are demarcated by natural and social boundaries. The northern part of this neighbourhood extends to an abandoned railway track and the southern part goes up to a canal. In addition to residents' settlements, this area has some important government institutions such as the Sri Lanka Atomic Energy Board, Automobile Engineering Training Institute, Kelanitissa power station complex and combined cycle power plant.

Figure 3. Map of Wadulla Grama Niladhari Division

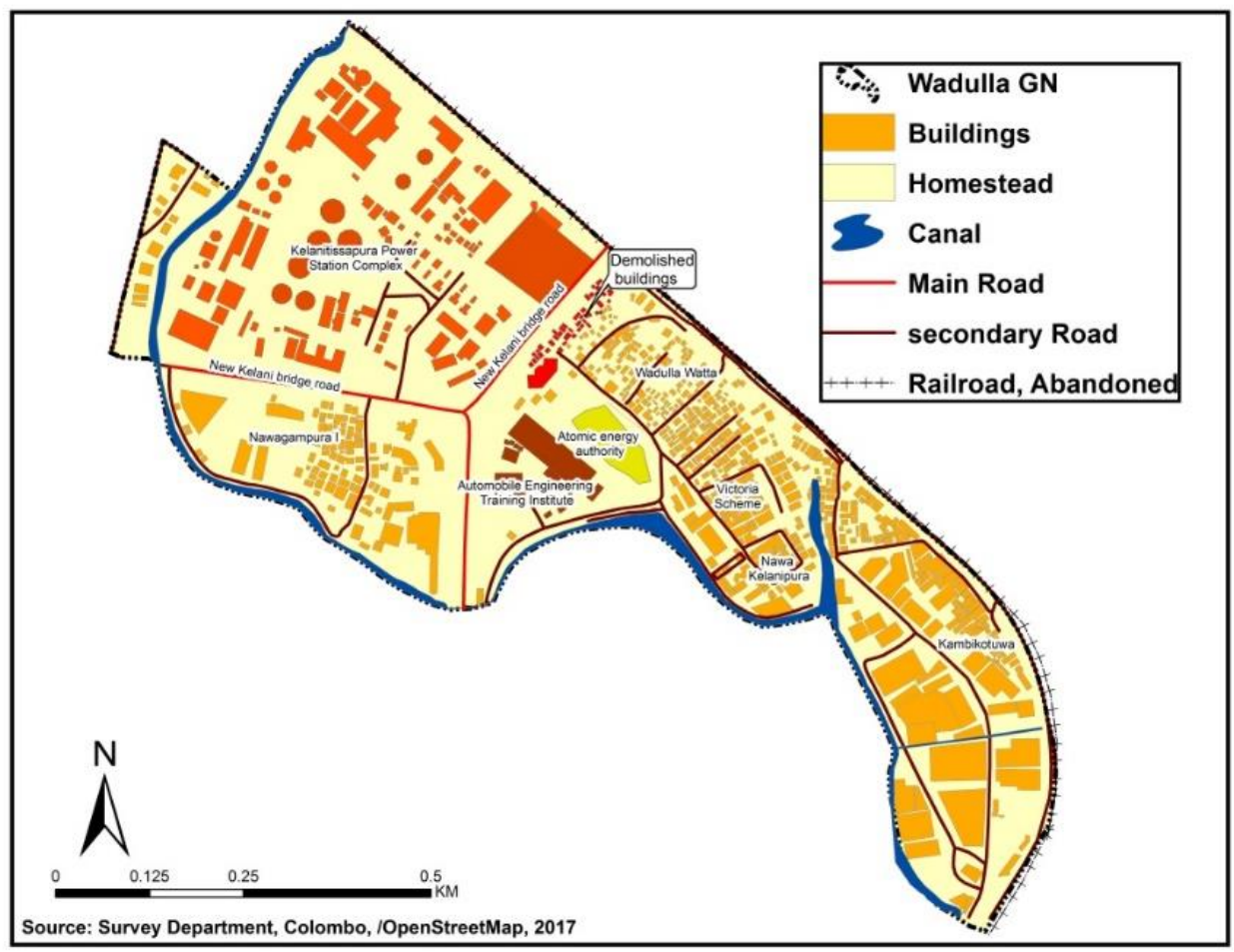

Source: Survey data 
Earlier, this area looked like a forest; thus people referred to it as "Wadulla" (meaning forest in Sinhala). In 1964, there were five Tamil families, five Muslim families, and around 30 Sinhalese families living in this neighbourhood. Over the years people from in and out of Colombo migrated to this neighbourhood. Currently, five to ten perches of land can be categorized as homestead land. This area is regularly affected by flooding of the Kelani River partly as a result of many environmentally sensitive places including the canal been encroached and covered by concrete to fill-up for building houses. Such illegal encroachments help create much needed space/land for building or expanding houses. During floods residents are either forced to live in the upper floor of their house or to move temporarily to safe places.

Sammanthranapura Grama Niladhari Division is located in Mattakkuliya adjoining Kelani River in Colombo 15 (see Figure 4). This settlement was established in 1976 for people who were evicted from their places of residence for infrastructural developments that took place for the hosting of Non-Aligned Summit. The name Sammanthranapura derived from 'Summitpura', literally meaning 'the town where the summit was held'. Earlier, this area was a marshy land and it was filled with debris/garbage when it was given to evicted people. More than 1000 families were evicted in this manner for the Summit and they moved to various areas within Colombo. Sammanthranapura is one such settlement. 
Figure 4. Map of Sammanthranapura Grama Niladhari Division

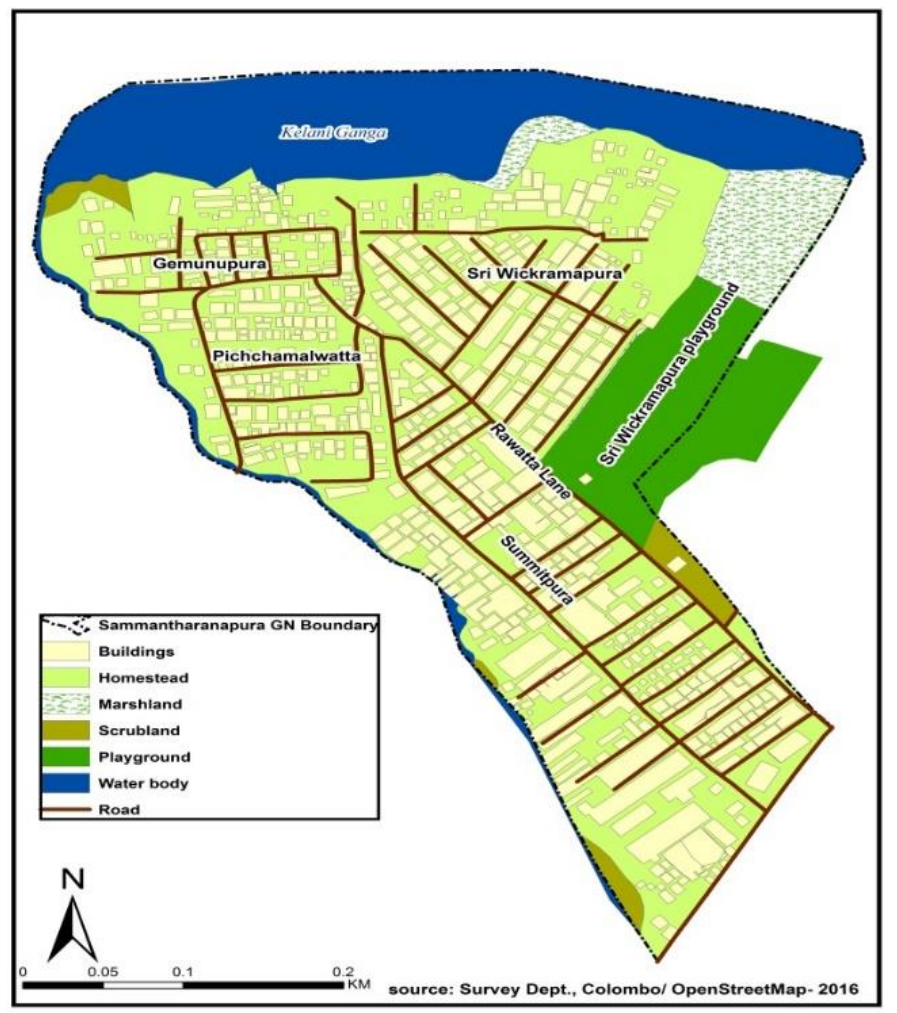

Source: Survey data

According to the Grama Niladhari, in 2017, this neighbourhood consisted of around 2000 families. Among them approximately 700 families lived in encroached lands. This multi-ethnic community consists of people from all main ethnic groups in Sri Lanka, with a Sinhalese majority.

\section{Findings and Discussion:}

Data generated from in-depth interviews were subjected to a manual thematic analysis to identify the material, subjective, and relational well-being of the residents. Data was analysed to see if the said well-being aspects were significant in the person's decision to migrate to the selected communities and to remain there.

\section{Material Well-being:}

One of the key factors that attract migrants to these underserved neighbourhoods is the "location". Both sites have prompt transport facilities which make it possible for the residents to comfortably reach any destination for employment and other services. The majority of residents consider Wadulla the "best place for poor people" (Nethi beri ayata hondama thena) 
because of various factors, particularly the economic benefits of living in the location. Researchers working in similar underserved communities in other locations have made similar findings (Mitra 2010; Owusu, Agyei-Mensah, and Lund 2008). Employment, transport facilities, affordable house rent, and daily consumables are some key elements that encourage low-income people to move into these neighbourhoods.

We looked for a house in many places. According to our financial status at the time, this was the only house we could afford. We didn't get any house in the other areas. The rent was low in this area only. If we want to rent a comfortable house, we need to pay around 17,000 rupees (Female, 34 years)

The location makes it possible for residents to get informal employment in nearby warehouses, container yards, factories, and markets. Most of these places can be reached on foot from the locations under study. Some other places like the Peliyagoda fish market and the Pettah Manning Market, which are located five to six kilometres away, can be reached easily by public transport. According to the Grama Niladhari, around 75\% of Sammanthranapura residents are labourers and their livelihood depends on the informal sector.

I don't think big. I just want to live in peace with the children. If there is a house and a good job, that is all I need. I can provide for my family with a good job. (Male, 43 years)

There are lots of jobs available. Like packaging work... this and that... There are lots of jobs around here, which I am planning to do. (Female, 38 years)

Some residents opted to stay in these neighbourhoods with the intention of educating their children in Colombo. Having an address in Colombo opens up the possibility of educating one's children in a "Colombo school" because, in Sri Lanka, schools are allocated based on the distance from home to school. Preference for a school in Colombo by residents of underserved communities, due to the better physical and human resources available in these schools, has been recorded previously (Lakshman, Ekanayaka, and Lakshman 2016).

We have our own house elsewhere. We have rented this house here. Everyone close to us is far away from us. They stay in Wattala and so on. We are living here because we want to educate our children. (Female, 38 years) 
Some residents were attracted to the material well-being that was provided in their current residence to the extent that they refused to move out of the current location even if the Government provides them housing facilities.

I don't like to live in the flats given by the Government. It will be like poultry shed... they will build multi-storey buildings and we cannot live there. If they force us to leave from here, we will leave only if they provide compensation for this place. (Male, 44 years)

Three housing patterns can be observed in these neighbourhoods, namely 1) permanent; 2) semi-permanent; and 3) temporary. The floor area of these houses range from 150 square feet to 600 square feet. Some dwellers build two storeyed houses which keeps them safe during floods. The majority of houses have pipe-borne water, electricity, and latrine facilities. Public water and toilets are also available for those who do not have these facilities in their houses. The majority of respondents live in their own houses. There are various types of documents that people highlight to claim house ownership. Only a few respondents have a housing card (Kudumbi patha) issued by the government and the rest of the people claim ownership through the tax number, i.e., a "T" number (which is a temporary number issued by the Grama Niladhari to get electricity and water supply), and utility bills.

Residents' satisfaction and happiness about house ownership and the general location seemed to differ based on these different housing types and conditions. For example, those with $\mathrm{T}$ numbers were concerned about their house being demolished one day and were, therefore, keen to move out of the neighbourhood.

We paid little by little... we purchased it for 250,000 rupees and I did some repair works. If they say $T$.... this is $T$..... There are three houses here with $T$ numbers. For these riverside houses, they have given this T number. So, they will demolish. (Male, 42 years)

The above example of 'T numbers' also depicts the way in which these people continue to be pushed around against their will by government policies. Even though they are likely to be paid compensation when their houses are demolished, it is very unlikely that they will be offered the worth of their current house or if they will be able to settle in a location as convenient as the current one.

Residents with their own houses, except the ones with ' $T$ numbers, seemed relatively happy with their housing arrangement and satisfied with the benefits offered by the location. Previous researchers also have found house ownership to provide an anchor in the community for the respondents 
(Carpenter, Daniere, and Takahashi 2004; Glaeser and Sacerdote 2000; Sampson, Raudenbush, and Earls 1997). The present research also found house owners to be happier and have a stronger hold in the community.

This is my own house. When we were living in Wattala, we had to search for money to pay the monthly house rent. The income... Now, I am thinking that... it is good we came here... be it a good place or bad place. We have a place to live. (Male, 67 years)

I was born in one place and now living in another place. But, actually I love this place very much. Because, the people are so good. There are people who live in the same place for 50 years, but they don't even know their neighbours. In my case, you will not be able to find a single person here who doesn't know me. If a person doesn't know me here, he must have been born yesterday or come to this place yesterday. (Male, 60 years)

Figure 5. Housing quality in community

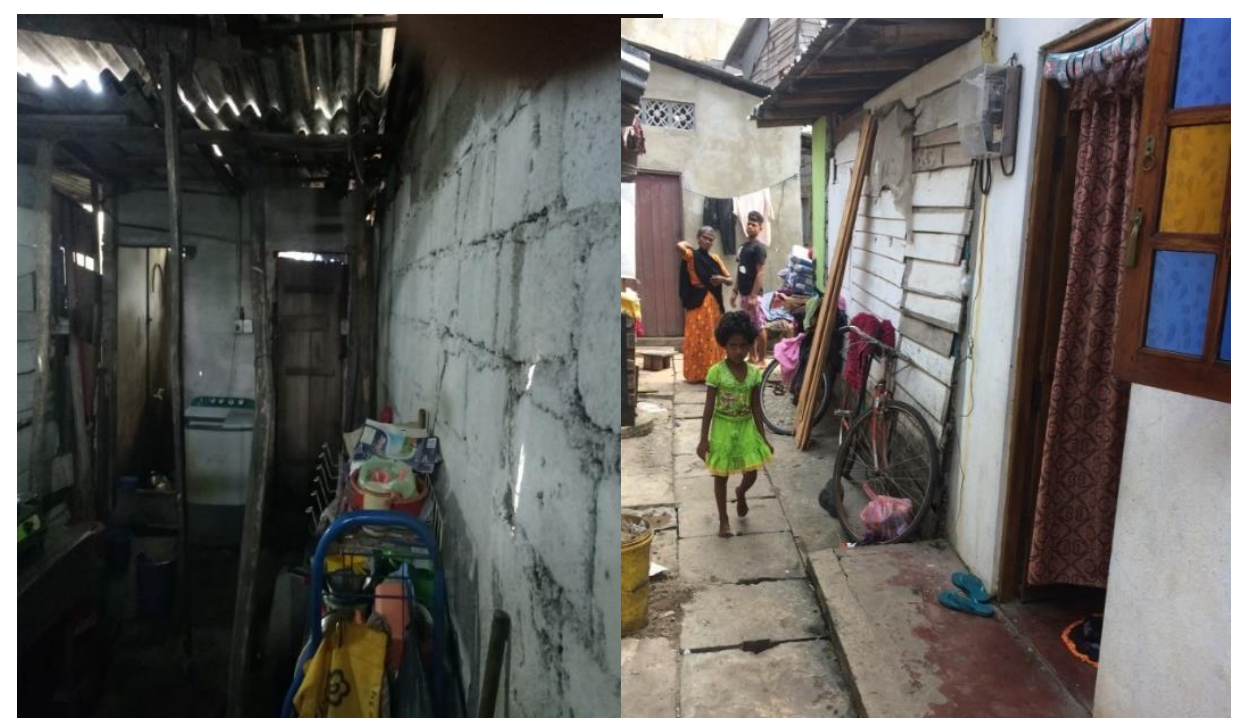

Significant numbers of residents live in rented houses. There are two systems of rent in practice. The monthly rent system requires people to pay advance money for two or three months and then pay the promised rent every month. When the tenant leaves that house in one or two years the landlord has to return the advance money after deduction of any dues. The other system is the "long lease" (Baddha). Here, the tenant pays a bulk of money at once and pays a small amount as rent (this rent is very low compared with the current rent rate in the area). In most cases, the landlord uses this money to either invest in some business or to settle debts. The landlord has to return that bulk 
amount to the tenant at the completion of the agreement period. Residents living in such leased houses were keen to have their own house.

We have taken this house by paying 400,000 rupees and we are paying 1,000 rupees rent per month... If we want to be happy we need a house and a vehicle. That is the only happiness. (Female, 43 years)

House ownership, for these residents in underserved communities, is not simply a matter of owning a house or not. It is a deciding factor that determines if a resident's name will appear in the voters' list. The resident has to provide documents to prove house ownership or a no objection letter from the landlord to the Grama Niladhari (GN) ${ }^{2}$ to ensure entry into the voters' list. In general, landlords are reluctant to give no objection letters to tenants because of a worry that the tenant may take over the house after residing in it for several years. Due to this same reason landlords do not usually extend the lease contract for more than two years. This necessitates the tenants to find a house every two years. Residents are denied several facilities such as school admission, and certificates of residence from the Grama Niladhari if their names do not appear on the voters' list.

We do not have voting power - we have not voted for a long period. House owners panic that tenants may claim house ownership if they live in the house for 5-10 years and get GN certification/letters for this address. Therefore, no house owner allows the tenants to take any type of letter with this address. (Female, 47 years)

Residents in these neighbourhoods enjoy not only affordable house rent but also daily consumables at cheaper prices. This is another factor which motivates people to remain in this type of underserved settlement.

In this neighbourhood you can get everything cheap for the amount that you have in your pocket. You can even get half a coconut, green chillies worth Rs. 10, 1/2 ounce milk powder. In this place, anyone can get their daily needs at affordable prices. (Male, 65 years)

A migrant mother had the following to say about affordable prices that match their daily needs:

${ }^{2}$ Government official in-charge of a Grama Niladhari division. 
There is something affordable to eat here. In Kurunegala, we have to buy a whole packet of milk. Here we can buy some milk powder for 20 or 50 rupees. (Female, 44 years)

There were some respondents who felt that the prices in Colombo are high and difficult to manage. However, these comments were made mostly based on a comparison between the "village" and "city" life with a sense of nostalgia. For example, the woman who made the following statement has moved into this neighbourhood after her marriage and has had to live in her husband's house built by his parents. This is more a case of "inheriting a house" rather than voluntarily opting to live in this location.

In terms of differences... Our village was good. For everything... we didn't feel any difficulties. In Colombo, people face difficulties. The price levels are high here. Those things are not a problem in the village... (Female, 39 years)

Hitherto, we examined the pull factors that stimulate people to move and live in these neighbourhoods. Residents were able to "find" enough "material reasons" to confirm their desire to migrate to and stay in the neighbourhood. Even with issues such as house ownership, inability to get their names into the voters' list and possibilities of forced relocation, these residents were satisfied with the material benefits offered by the location.

Additionally, there were some other negative elements, not directly connected with house ownership that created concerns for the residents about their material well-being. Lack of infrastructure facilities such as a proper drainage system and sub-roads were mentioned by many respondents during interviews. These infrastructural issues are usually associated with further problems such as diseases and pollution (Rashid 2009). Respondents were of the view that the living conditions of this neighbourhoods will drastically improve if the Government paid proper attention to infrastructural issues.

Our only hope is that the Government would fulfil its responsibility towards us by making and maintaining the roads, drainage system etc. If they do these things properly... that is enough. (Male, 44 years)

Lack of development is the problem... when we enter into this area... you can see open drains... It creates some odd feeling... other than that... the flood. If proper roads are available... the problem will be solved. (Male, 44 years) 
Figure 6. Environment during the rainy season

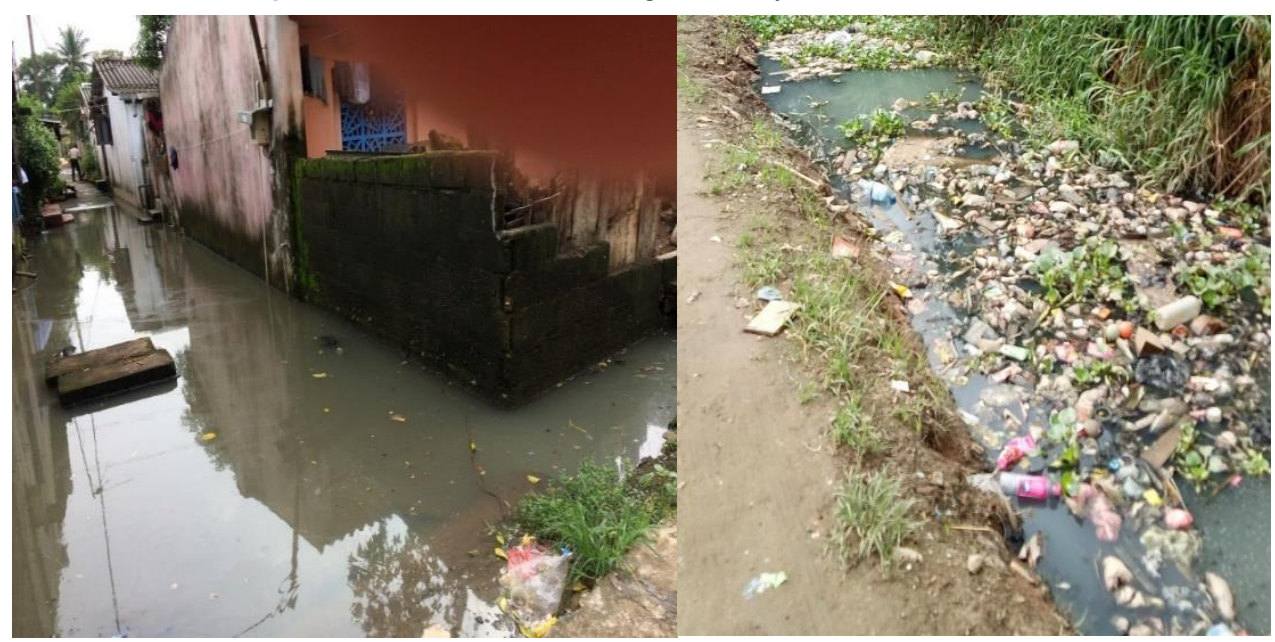

In spite of these infrastructural problems that create various health and other difficulties for the residents (See Figures $5 \& 6$ for quality of housing), they continued to appreciate the material benefits brought in by the "location". The following statement by one of the respondents clearly shows that material well-being is the strongest factor that keeps them attracted to the neighbourhood.

We don't want to stay here continuously. Even now we are searching for a suitable house. Recently also we tried to move from here. If we can get the income correctly according to our needs, we have the idea to change the place. (Female, 38 years)

The resident is clearly stating that her current location is the best place for them given their 'current' income. Easy access to informal economic activities and the low cost of living seemed to be the two main factors appreciated by the respondents in terms of their material well-being.

\section{Relational Well-being:}

Statements by many respondents reveal that they enjoy strong social networks with family and friends. However, the extent of community engagement and strength of social networks are decided by dwellers' migration period (Carpenter, Daniere, and Takahashi 2004) and their employment. Non-migrants' and informal sector employees' networking ability is higher than that of migrants and formal employees. Non-migrants and informal sector employees seem blessed with a more advantageous position to ensure possibilities of anchoring themselves in the community strongly (Carpenter, Daniere, and Takahashi 2004) than their migrant, formal sector employee counterparts. Non-migrants have the advantage of knowing 
the area and community well while the informal sector employees have the (relative) advantage of time availability to socialize with fellow community members. People use their social networks for various reasons such as child care, finding jobs (particularly informal labour work), accessing instant loans, getting support in emergencies, organizing religious festivals and New Year celebrations. Migrants also gradually adapt to this atmosphere and mingle with other community members in the neighbourhoods.

When I first came here, I was unaware of their way of life. Now I have a better understanding. When I started constructing the house I actually realized how helpful they were. (Female, 44 years)

The above statement by a female migrant indicates that migrants and non-migrants gradually mingle with each other over time. Both research sites contain ethnically and culturally diverse groups of people and in some cases their social networks cut across ethnic and cultural boundaries. Inter-ethnic marriages are also common and they stimulate inter-ethnic coexistence.

No, nothing like that. No discrimination. Nothing like that. We mingle with Muslims, Sinhalese and Christians. Nothing like that. If we don't have any problem with anyone, we can have a good life anywhere. (Male, 44 years)

The people in the area like us very much. If we say that we are going to move out from this place, they will plead with us not to go. People are that much closer to us. Even though they are not our relatives, they mingle with us in such a way. (Female, 46 years)

However, some respondents, particularly those who have migrated from villages, struggle to come to terms with the lifestyle of these communities. This is clearly a case of migrants not being able to anchor themselves in the community due to the contrasting lifestyles in urban and rural settings (See Figure 7 for how members of the community gather for festive celebrations and cleaning of the surrounding area). 
Figure 7. Cultural and social life

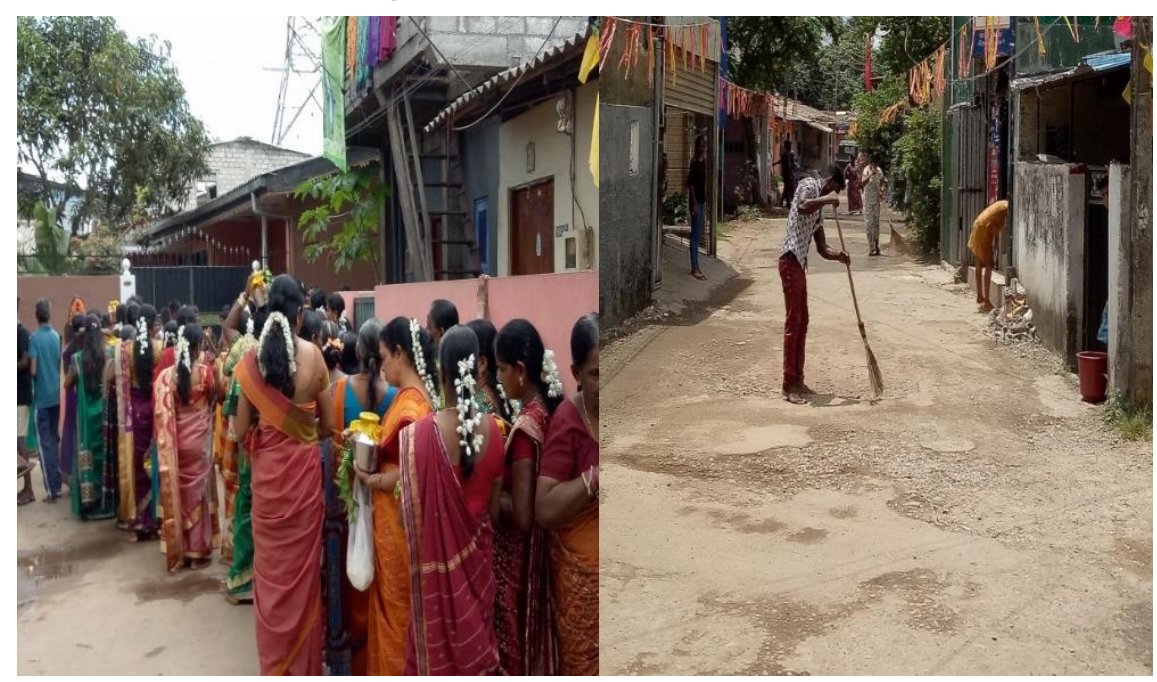

We have to be little cautious as well, because it will be dangerous for us to mingle with certain people. (Female, 33 years)

Even now... this place... I don't like it. The people here are not good. They don't have the willingness to help others... not like our village people. If you have a problem, the people in the village come quickly to help... The people here are not friendly, not suitable to associate... I don't know any good thing here... Even during an emergency situation, no one here will come to help. The people in this place are like that (Female, 36 years)

Likewise, people in formal employment too had practical difficulties of engaging in social relationships largely due to time constraints imposed by their employment. Furthermore, the guarantee of a fixed income that comes from formal employment may also be creating a weaker need/ desire to integrate with the community.

I don't waste much time here. I go to work at 8.00 a.m. in the morning... I stay at home only on Sundays. I don't have much spare time... I cannot say that all the people living here are not good. Good people also live here. Everyone takes care of their own business and stay. We also live here. We don't mingle with others that much here. We go to our work and come back home. That's it. (Male, 44 years)

There was clearly a gendered dimension to social relationships in the two locations. Women were sceptical about forming widespread social 
networks across the community. They preferred small-scale relationships which were formed with, for example, their immediate neighbours. Such neighbours would come to their aid for childcare, money borrowing, kitchen help etc.

They come to help in emergencies. I am alone in the afternoons. Husband is away, working. If someone from outside comes and shouts here, they will come and silence him... They will come to my aid. (Female, 44 years)

This pattern was identified by previous researchers too (Lakshman, Herath, Alikhan, and Ekanayake 2016). On the other hand, men were more concerned about forming wider relationships that ran across the community. Such relationships took the form of community associations.

If you want to create unity among communities... we have to start a society with at least four people... a society in name only... regardless of whether it functions or not... We have to use a popular person to initiate a society. So, the old aged people stay behind us. Also, we need to form a sports club by using the youth. So, the youngsters are also behind us. Thereafter, a tuition centre for the kids. So that the kids also come to our side. So, the community comes under our control and they will listen to what we say. Also, we have to do something for them. Rather than running a society for fun, we should do something. (Male, 60 years)

Respondent's views were divided on how their social relationships were useful for their well-being. However, even the one's holding negative attitudes about their social relationships did not bring it up as a reason for wanting to move out of the community. Those who were not appreciative of the kind of relationships that were possible in the community would keep to themselves and continue to co-exist in the community without forming strong relationships. "No one tells anything to us. We earn and eat. We don't depend on anyone" is a statement by a 67 year old male respondent that clearly depicts this attitude. People possessing this kind of non-integrative attitude seemed "afraid" to form relationships due to the subjective assessment they had about their fellow residents. The widely known violent nature of people in these underserved communities seemed to create this reluctance towards forming social relationships.

\section{Subjective Well-being:}

In both neighbourhoods, unlike with material and relational wellbeing, people struggle with subjective well-being. Here, subjective well-being 
can be interpreted as a type of psychological stress experienced by the residents as a result of the social and physical surrounding in their neighbourhoods. People feel uncomfortable about their lifestyle due to many factors. Some people are not satisfied with their house, especially those living in temporary and semi-permanent houses. They always attempt to upgrade their housing condition but this is very difficult to achieve with their income. This is a common concern pertaining to their physical environment. Some people are not satisfied with their social networks, i.e., the social environment. They often complain that the kind of social environment in which they have to manage gives a bad impression about them to the outside world even if their house looks nice.

The children go to school. They should be able to go on the road. We feel like we are prisoners. Our children should have the ability to live freely. That is my expectation. We may just live for a few years and then die. Our children will have to live afterwards. (Male, 43 years)

Having to live in a neighbourhood with unwelcome subjective weelbeing can have a detrimental impact on people's self-esteem (Suh, 2003). People who were not comfortable with their physical and/or social environment preferred to remain hidden from their relatives and friends; that is, they were embarrassed to bring friends and relatives to the house. Even the children were reluctant to bring their friends.

Even my children tell me to plaster this house. They say that they are unable to bring their friends here. (Female, 39 years)

Urban underserved communities across the world have a reputation for violence and criminal activities (Blau 1960; Brennan-Galvin 2002; FelbabBrown 2011; Lakshman, Herath, Alikhan, and Ekanayake 2016). Respondents from the two study locations commonly complain about underworld thugs, gangsters, and illegal drug dealers and abusers. Activities of gangsters are much higher in Wadulla than in Sammanthranapura. In the early 1980s, notorious underworld figures and gang leaders have lived in Wadulla and their reputation is still remembered by non-members of the community. Whenever "visiting" these communities is brought up, people still make reference to these incidents to discourage the visit.

Nowadays, there are no gangsters and thugs like those days, but still outsiders have bad impressions about this area. That's why decent, educated people will not remain here. People go abroad and try to earn money to move from here to other places like Wellawatta, Colpetty or Bambalapitiya (Female, 74 years). 
Illegal activities in these neighbourhoods sometimes lead to physical fights which end up in shooting or stabbing. Illegal drug dealing is one key factor causing this kind of gang fights.

This place is not good. Some people here kill other people for money. Even hiring a three-wheeler to get here is challenging sometimes. They refuse to drive here because of this reputation. If we say "Mattakuliya", no one will come. (Female, 39 years)

Many respondents with children are under pressure about the future of their children. They feel this environment, both physical and social, are not suitable for their children because it restricts their potential.

It is difficult to raise our children. Lot of filthy words... those things are too much. We cannot raise them indoors everyday... can we? (Male, 42 years)

Although they manage in these neighbourhoods, the above factors promote an invisible existence.

Wherever I go, I always mention my residence as Yatiyanthota. It is not suitable to mention Mattakkuliya as this is a problematic area. (Female, 39 years)

It is worrying. Three brothers... the sons of my father's younger brother.... They are having good lives... All of them are better off... But, they never come to my house... When they come they say that they fear coming to Samithpura... Mostly my relatives. Even if the people from his side come here, they would say the same. They will say that... "you stay the same as in the village, here." Then it would be very hurtful to our hearts. (Female, 38 years)

These concerns pertaining to subjective well-being were also related to identity formation of individuals, particularly the young, in the community. They did not wish to be identified as coming from the said neighbourhoods.

It is meaningless. Wherever we stay, our place is always our place. My grandson, he was born here. If I go to our village and mention him as a Colombo native, he becomes angry. He asks, "Why you are saying like that granny? Please say my place is Nawalapitya, Don't say like this again." (Female, 67 years)

There is no stature here. The society rejects us. The child might have a problem at a certain time by associating this place as home. Those who stay will stay on. Some say that the 
background has nothing to do with a child's development. (Female, 44 years)

Resident's future aspirations seem to be formed around the dissatisfaction felt about "social attitude" held by outsiders about the physical and social environment of the community. These aspirations confirm the dissatisfaction felt by residents in terms of subjective well-being. Some of them desire to build their own house, while others want to reconstruct the existing house. Some others desire to completely move out of the current location. Residents also aspire to educate their children to make sure that their life circumstances are better than that of the parents. The current location does not seem to provide the environment necessary for such possibilities. Factors that promote their material well-being seem pivotal towards attracting and retaining them in the neighbourhood. Relational well-being facilitates this attraction to some extent. However, the combination of material and relational well-being does not seem to necessarily bring about subjective well-being. Even some residents with positive attitudes about the social relationships in the neighbourhood aspired to leave the community because of concerns pertaining to subjective well-being. In other words, relational well-being alone did not seem like an adequate factor that could keep the residents attracted to the neighbourhood.

If I can buy some other house, I will leave here...because of the environment here. Although the neighbours are good, it is not just about that. (Male, 43 years)

The material well-being found in these neighbourhoods seem to compensate for the inadequacies of subjective well-being felt by the residents. Coping with these inadequacies was made possible by material benefits offered by the location.

In any way... we don't like to stay here. We are looking for an opportunity to go out anywhere. But, we don't have that much of capacity. If we want to go out, we have to give key money to take a shop... Even if we want to take a house, we have to pay this key money. There are no places available in other areas for a low cost as here... Because of that, anyway... we are continuing here. It will be difficult to raise our children in this place. (Male, 42 years)

It is difficult to say that the "realistic" state of well-being outlined by Pouw and McGregor (2014) exists in the neighbourhoods studied. At the same time it would be misleading to assume that these individuals continue in these communities in a zero well-being setting. Though they do not have the three 
dimensions of well-being intersecting perfectly, they do have at least two dimensions, i.e., material and relational well-being intersecting well enough to "retain" them in the community. Even the ones who explained their existence in the community as one of "desperation" were able to "find" reasons to remain in the community, particularly focusing their attention on the affordable nature of daily life in the neighbourhood.

\section{Conclusion}

The paper analysed data obtained through 30 in-depth interviews with residents in two underserved communities in Sri Lanka using the well-being model presented by Pouw and McGregor (2014). The three dimensions of well-being, namely 1) material, 2) relational, and 3) subjective, were analysed by looking at 1) housing quality, quality of physical environment, employment, and educational opportunities and cost of living; 2) nature and use of social relations; and 3) external perceptions of the community and its impact on the emotions of residents.

Considering the fact that most of the residents belonged to the lowincome category, it was evident that they were attracted to the location by cheap housing, low cost of living, better opportunities of informal employment and educational opportunities for the young. Even though there was some discontent in terms of physical environment, they still coped with these neighbourhoods because of its location and affordability. Many who wished to leave the neighbourhood could not do so because life outside of these communities was too expensive for their income. This ideal match between their income and expenses seemed to provide adequate conditions for the residents to be content, or at least 'find' a suitable reason for remaining in the community.

Relational well-being and subjective well-being was affected mostly by the violent reputation that is usually attributed to these underserved communities. Residents, particularly new migrants to the location, were reluctant to form relationships with others in the community because of this concern. These neighbourhoods have had thugs and gangsters living amongst them in the past. Even though the threat is currently either absent or weak, migrants still seem reluctant to believe that these areas are safe. However, over time, they too seem to get accustomed to and be happy with the kind of social relationships that are formed in these neighbourhoods. People in formal employment also seemed to hold reservations about social ties in these neighbourhoods. But this was mostly a situation caused by the unavailability of time to socialize as a result of being in formal employment. Therefore, in terms of social relationships, there was clearly a difference in the strength of relationships formed by migrants as opposed to non-migrants and the informally employed as opposed to the formerly employed. In general, the 
residents seemed to be coping well, though they may not be happy, with the kind of social relationships offered by the neighbourhood.

Subjective well-being seemed to be the area with which the residents felt the most amount of discontent. They were clearly struggling to come to terms with the identity of their community and the social recognition offered by the neighbourhood. They were not at all happy with how their neighbourhood was perceived by people living outside the community. They were always made to feel that they lived in an unsuitable place which offered bleak opportunities of improved living conditions. These sentiments clearly made the residents feel a desire to move out of the neighbourhood.

Instead of a situation where the three dimensions of well-being outlined by Pouw and McGregor (2014) intersecting perfectly to create a realistic well-being, the authors observed a situation of material and relational well-being intersecting to create a more practical kind of well-being in the communities studied. Of the two, material well-being had the strongest power to attract and retain residents in the neighbourhoods while relational wellbeing played a supportive role in terms of pulling people into the community. Subjective well-being, on the other hand, was identified as the strongest reason that has the capacity to push people away from the community. However, this single push factor was not strong enough to overpower the pull effect of material and relational well-being, particularly because of the residents' lowincome. The material benefits of living in the location facilitated by the social ties offered by the neighbourhood kept these residents attracted and attached to these underserved communities.

\section{Acknowledgments}

The authors would like to thank the Centre for Migration Research and Development (CMRD) for commissioning the paper. They are thankful to Professor Michael Collyer, Principal Investigator and Dr. Danesh Jayatilaka, Co-Investigator of the Migrants on the Margins research study. Thankfully acknowledging the support provided by Sakeena Alikhan for preparing the maps of the study sites.

\section{References:}

1. Arularasi, B. \& Alikhan, M.M. (2015). Plantation to urban: Phenomenon and causes of youth migration in the Pitakanda Estate, Matale. Volume: 19, University of Peradeniya: Peradeniya University International Research Session.

2. Amin, A. (2013). The urban condition: A challenge to social science. Public Culture, 25(2 70), 201-208. 
3. Atkinson, R. (2003). Life story interview, in: Lewis-Beck M., Bryman, A.E. \& Liao, T.F, (Eds.), The SAGE encyclopaedia of social science research methods. Sage Publications, Inc., California.

4. Bayat, A. (2008). Cairo cosmopolitan: living together through communal divide, almost, in The other global city (pp. 179-201). Routledge Taylor \& Francis Group.

5. Biswas-Diener, R., \& Diener, E. D. (2006). The subjective well-being of the homeless, and lessons for happiness. Social Indicators Research, 76(2), 185-205.

6. Blau, P. M. (1960). Structural effects. American sociological review, 178-193.

7. Brennan-Galvin, E. (2002). Crime and violence in an urbanizing world. Journal of International Affairs, 123-145.

8. Camfield, L., Choudhury, K., \& Devine, J. (2009). Well-being, happiness and why relationships matter: Evidence from Bangladesh. Journal of Happiness Studies, 10(1), 71-91.

9. Camfield, L., Crivello, G., \& Woodhead, M. (2009). Wellbeing research in developing countries: Reviewing the role of qualitative methods. Social Indicators Research, 90(1), 5.

10. Carpenter, J. P., Daniere, A. G., \& Takahashi, L. M. (2004). Cooperation, trust, and social capital in Southeast Asian urban slums. Journal of Economic Behavior \& Organization, 55(4), 533551.

11. Department of Census and Statistics. (2015). Census of population and housing, Ministry of Policy Planning and Economic Affairs, Colombo.

12. Cook, K.E. (2008). Marginalized populations in: Given. L.M. (Ed.). The SAGE encyclopaedia of qualitative research methods. SAGE Publications, Inc., California.

13. Datta, A. (2012). "Mongrel city": Cosmopolitan neighbourliness in a Delhi squatter settlement. Antipode, 44(3), 745-763.

14. D'Cruz, C., McGranahan, G., \& Sumithre, U. (2009). The efforts of a federation of slum and shanty dwellers to secure land and improve housing in Moratuwa: from savings groups to citywide strategies. Environment and Urbanization, 21(2), 367-388.

15. Felbab-Brown, V. (2011). Bringing the State to the slum: Confronting organized crime and urban violence in Latin America. Brookings Institution, December.

16. Fuentes, N., \& Rojas, M. (2001). Economic theory and subjective wellbeing: Mexico. Social Indicators Research, 53(3), 289-314.

17. Glaeser, E. L., \& Sacerdote, B. (2000). The social consequences of housing (No. w8034). National Bureau of Economic Research. 
18. Gough, I., \& McGregor, J. A. (Eds.). (2007). Wellbeing in developing countries: from theory to research. Cambridge University Press.

19. Van Horen, B. (2002). City profile: Colombo. Cities, 19(3), 217-227.

20. Kvale, S. (2006). Dominance through interviews and dialogues. Qualitative inquiry, 12(3), 480-500.

21. Lakshman, I. M., Ekanayaka, A., \& Lakshman, R. W. (2017). Going to school from a relocated urban community: Struggling for education within imposed walls. Migration and Development, 6(2), 198-214.

22. Lakshman, I., Herath, D., Mohommad, A., \& Ekanayake, A. (2016). Experiences of a relocated community in Colombo: case study of Sinhapura, Wanathamulla. International Centre for Ethnic Studies, Colombo, Sri Lanka.

23. Mahmud, M., \& Sawada, Y. (2018). Happiness in life domains: evidence from rural Bangladesh. In Economic and Social Development of Bangladesh (pp. 233-250). Palgrave Macmillan, Cham.

24. Mitra, A. (2010). Migration, livelihood and well-being: Evidence from Indian city slums. Urban Studies, 47(7), 1371-1390.

25. Owusu, G., Agyei-Mensah, S., \& Lund, R. (2008). Slums of hope and slums of despair: Mobility and livelihoods in Nima, Accra. Norsk Geografisk Tidsskrift-Norwegian Journal of Geography, 62(3), 180190.

26. Perera, N. (2008). The planners' city: the construction of a town planning perception of Colombo. Environment and Planning A, 40(1), $57-73$.

27. Pouw, N., \& McGregor, A. (2014). An Economics of Wellbeing: What would economics look like if it were focused on human wellbeing?. IDS Working Papers, 2014(436), 1-27.

28. Rashid, S. F. (2009). Strategies to reduce exclusion among populations living in urban slum settlements in Bangladesh. Journal of health, population, and nutrition, 27(4), 574.

29. Rojas, M. (2005). A conceptual-referent theory of happiness: Heterogeneity and its consequences. Social Indicators Research, 74(2), 261-294.

30. Roy, A. (2011). Slumdog cities: Rethinking subaltern urbanism. International journal of urban and regional research, 35(2), 223-238.

31. Sampson, R. J., Raudenbush, S. W., \& Earls, F. (1997). Neighbourhoods and violent crime: A multilevel study of collective efficacy. Science, 277(5328), 918-924. Sevanatha. 2013. The Case of Colombo, Sri Lanka. Sevanatha Urban Resource Centre, Colombo. 
32. Silva, K. T., \& Athukorala, K. (1991). The Watta-Dwellers: A sociological study of selected urban low-income communities in Sri Lanka. University Press of Amer.

33. Suh, E. M. (2003). Self, the hyphen between culture and subjectivewell-being, in: Diener, E., \& Suh, E. M. (Eds.). Culture and subjective well-being. MIT press.

34. Warren, C.A.B. (2004). Interviewing in qualitative research, in: LewisBeck M., Bryman, A.E. \& Liao, T.F, (Eds.), The SAGE encyclopaedia of social science research methods. Sage Publications, Inc., California. 